\title{
Downregulation of miR-136 promotes the progression of osteosarcoma and is associated with the prognosis of patients with osteosarcoma
}

\author{
${\text { YANCHEN } \mathrm{CHU}^{1 *}, \text { XIAOLI HU }}^{2^{*}}$, GUANGFENG WANG ${ }^{3 *}$, ZHIJIE WANG $^{1}$ and YANJIN WANG ${ }^{4}$ \\ ${ }^{1}$ Department of Spinal Surgery, Affiliated Hospital of Qingdao University, Qingdao, Shandong 266000; \\ ${ }^{2}$ Department of Obstetrics and Gynecology, Women and Children's Hospital of Linyi City, Linyi, Shandong 276000; \\ ${ }^{3}$ Department of Medical Administration, Affiliated Hospital of Qingdao University, Qingdao, Shandong 266000; \\ ${ }^{4}$ Department of Orthopedics, Affiliated Hospital of Qingdao University, Qingdao, Shandong 266000, P.R. China
}

Received August 1, 2018; Accepted February 2, 2019

DOI: $10.3892 / \mathrm{ol} .2019 .10203$

\begin{abstract}
Osteosarcoma (OS) is the most common bone tumor in children and young adults, and is an aggressive tumor with poor prognosis. MicroRNAs (miRNAs) are aberrantly expressed in various types of cancer, and contribute to cancer tumorigenesis and progression. In the present study, the potential prognostic value and biological function of miRNA-136 (miR-136) in OS was investigated. Reverse transcription-quantitative polymerase chain reaction analysis was used to evaluate the expression of miR-136 in OS tissues and cell lines. Kaplan-Meier survival analysis and Cox regression analysis were conducted to investigate the prognostic significance of miR-136. Various in vitro cell based assays were used to evaluate the effects of miR-136 on the biological behavior of OS cells. A luciferase assay was performed to determine the key miR-136 targets associated with OS. The expression of miR-136 was significantly downregulated in osteosarcoma tissues and cells compared with the normal controls (all $\mathrm{P}<0.05$ ). Decreased miR-136 expression was significantly associated with Enneking staging $(\mathrm{P}=0.030)$ and distant metastasis $(\mathrm{P}=0.016)$. Decreased miR-136 expression in patients was associated with shorter overall survival compared with patients with increased expression levels (log-rank test; $\mathrm{P}<0.05$ ). The expression of miR-136 was indicated as an independent prognostic factor for the patients (hazard ratio $=0.496$; $95 \%$ confidence interval $=0.250-0.987 ; \mathrm{P}=0.046)$. MTT, transwell and Matrigel assays demonstrated that upregulation of miR-136 decreased proliferation, migration and invasion of OS cells. Bioinformatics and luciferase assays demonstrated that migration and invasion
\end{abstract}

Correspondence to: Dr Yanjin Wang, Department of Orthopedics, Affiliated Hospital of Qingdao University, 16 Jiangsu Road, Qingdao, Shandong 266000, P.R. China

E-mail: gong35518che@163.com

*Contributed equally

Key words: microRNA-136, prognosis, osteosarcoma, progression enhancer 1 (MIEN1) is a direct target of miR-136. Together, the results suggested that miR-136 functions as a tumor suppressor gene to regulate proliferation, migration and invasion of OS cells. MIEN1 was a potential target of miR-136. Additionally, miR-136 may serve as a prognostic biomarker for OS.

\section{Introduction}

Osteosarcoma (OS) is the most common primary malignant type of bone malignancy in adolescence and is characterized by the formation of immature bone or osteoid tissues from spindle matrix cells (1). Due to the high degree of malignancy of OS and early metastasis to the lungs, the majority of the patients present pulmonary micrometastasis at the primary diagnosis (2). At present, the combination of surgical resection and chemotherapy is the most effective treatment $(3,4)$. Despite a significant improvement in the 5-year overall survival for patients, the cure rate for patients with OS has not improved and patients with metastatic or relapsed disease have a poor prognosis $(5,6)$. Therefore, identifying more precise prognostic biomarkers and novel approaches to the treatment of OS is necessary to improve the outcome of patients with OS.

MicroRNAs (miRNAs) are a group of short non-coding RNAs (18-25 nucleotides in length) that regulate post-transcriptional gene expression by targeting the 3' untranslated region (3'-UTR) of mRNA (7). An increasing number of studies have demonstrated that miRNAs serve crucial roles in various biological processes, including inflammation, cell proliferation, migration, invasion, apoptosis and differentiation (8-10). Depending on their dysregulation, miRNAs may serve as tumor suppressors or oncogenes in tumorigenesis processes, which contribute to cancer metastasis by influencing cell proliferation and invasion $(11,12)$. Overexpression of miRNA-34a inhibited the migratory and invasive ability of OS cells by repressing the expression of CD44 antigen, serving as a tumor suppressor in the metastasis of OS cells (13). A previous study by Mosakhani et al (14) identified miRNA-136 (miR-136) and its target gene, nuclear factor $1 \mathrm{~B}$-type, as novel biomarkers that may aid in distinguishing primary giant cell tumors of bone with an increased risk for metastasis. Previous studies have additionally demonstrated that miR-136 is involved in the progression 
of a number of different types of cancer, including cervical carcinoma, hepatocellular carcinoma, and colon cancer (15-17). However, the role of miR-136 in OS remains unclear.

In the present study, the expression patterns and prognostic significance of miR-136 in patients with OS was investigated. Additionally, the effects of miR-136 on the biological behaviors of cancer cells were assessed.

\section{Materials and methods}

Patients and tissue samples. OS tissue and matched adjacent normal tissue specimens (located $>3 \mathrm{~cm}$ away from the tumors) were obtained between January 2007 and February 2012 from 116 patients with OS who underwent surgery at The Affiliated Hospital of Qingdao University (Qingdao, China). All the tissues were verified and experienced pathologists confirmed the tissue stages, according to the National Comprehensive Cancer Network guidelines $(18,19)$. The OS tissue and normal tissue specimens were snap-frozen in liquid nitrogen following surgery and subsequently stored at $-80^{\circ} \mathrm{C}$ until use. The inclusion criteria were: All patients were pathologically diagnosed with OS, none of the enrolled patients received any therapy prior to surgery. and all patients had complete clinical, pathological, and follow-up information. All patients agreed to participate in the present study and provided written informed consent prior to surgery, and the Ethics Committee of The Affiliated Hospital of Qingdao University approved the protocol. The characteristics of the patients are summarized in Table I. The 5-year follow-up information was updated for the subsequent analysis.

Cell lines and transfection. Human OS cell lines HOS and U2OS and the normal osteoblast cell line NHOst were obtained from The American Type Culture Collection (Manassas, VA, USA) and cultured in RPMI 1640 medium (Gibco; Thermo Fisher Scientific, Inc., Waltham, MA, USA) supplemented with heat-inactivated $10 \%$ fetal bovine serum (FBS; Gibco; Thermo Fisher Scientific, Inc.) at $37^{\circ} \mathrm{C}$ in a humidified incubator with $5 \%$ $\mathrm{CO}_{2}$. The miR-136 mimic (5'-ACUCCAUUUGUUUUGAUG AUGG-3'), miR-136 inhibitor (5'-CCAUCAUCAAAACAA AUGGAGU-3'), mimic negative control (NC) (5'-TTCTCCGAA CGTGTCACGT-3') or inhibitor NC (5'-UUCUCCGAACGU GUCACGUTT-3') were synthesized by Shanghai GenePharma Co., Ltd. (Shanghai, China). A total of $5 \times 10^{4}$ cells were seeded into the wells of a 6 -well plate. On the subsequent day, the cells were transfected with miR-136 mimic, miR-136 inhibitor or the respective miRNA-NCs (mimics NC and inhibitor NC) using Lipofectamine ${ }^{\circledR} 2000$ (Invitrogen; Thermo Fisher Scientific, Inc.) with a final oligonucleotide concentration of $20 \mathrm{nmol} / 1$, according to the manufacturer's protocol. As a negative control, transfection reagent alone was added to the cells as the mock. The transfection efficiency was detected by reverse transcription-quantitative polymerase chain reaction (RT-qPCR) analysis after $48 \mathrm{~h}$.

$R N A$ extraction and $R T-q P C R$. Total RNA was extracted from the tissue samples or the cells using TRIzol ${ }^{\circledR}$ reagent (Invitrogen; Thermo Fisher Scientific, Inc.) according to the manufacturer's protocol. The purity of RNA was obtained by calculating the ratio of optical density of absorbance at 260/280 nm using NanoDrop ND-1000 (Thermo Fisher Scientific, Inc.). The purified total RNA was reverse transcribed to cDNA using M-MLV reverse transcriptase (Promega Corporation, Madison, WI, USA) according to the manufacturer's protocol. The thermocycling condition for reverse transcription were as follows: $25^{\circ} \mathrm{C}$ for $5 \mathrm{~min}, 42^{\circ} \mathrm{C}$ for $60 \mathrm{~min}, 72^{\circ} \mathrm{C}$ for $10 \mathrm{~min}$. The relative $\mathrm{miR}-136$ expression was analyzed by RT-qPCR, which was performed using SYBR Green Premix Ex Taq (Takara Bio, Inc., Otsu, Japan) with an ABI 7500 instrument (Applied Biosystems; Thermo Fisher Scientific, Inc.). Relative expression was calculated using the $2^{-\Delta \Delta \mathrm{Cq}}$ method with U6 as the internal control (20). The primer sequences and thermocycling conditions of miR-136 and U6 used were as previously described $(21,22)$.

Cell proliferation assay. The cell proliferation of HOS or U2OS cells transfected with NC, miR-136 mimics or miR-136 inhibitor was measured using the colorimetric MTT method. HOS and U2OS cells were seeded into 96-well plates at a density of $5 \times 10^{3}$ cells/well and transfected. After 48 h, $10 \mu 1 \mathrm{MTT}(5 \mathrm{mg} / \mathrm{ml}$; Sigma-Aldrich; Merck KGaA, Darmstadt, Germany) was added to each well and the cells were incubated at $37^{\circ} \mathrm{C}$ for $4 \mathrm{~h}$. Subsequent to incubation, the medium was removed and $100 \mu \mathrm{l}$ dimethyl sulfoxide (Sigma-Aldrich; Merck KGaA) was added to the wells to dissolve the formazan crystals. A wavelength of $490 \mathrm{~nm}$ was used for the colorimetric analysis with a Multiskan MK3 (Thermo Fisher Scientific, Inc.). Experiments were repeated in triplicate.

Colony-forming assay. Following transfection, cells were plated at a density of 300 cells/well in a 6 -well plate and incubated at $37^{\circ} \mathrm{C}$. The culture medium was replaced according to the change of $\mathrm{pH}$ of the medium, as determined by the phenol red indicator in the culture medium. After 14 days, cells in each well were washed carefully with PBS, fixed with methanol for $15 \mathrm{~min}$ and stained for 10 min with Giemsa at room temperature. Subsequently, cell colonies (groups $>50$ cells) were counted under a light microscope (magnification, $\mathrm{x} 40$ ). The test was independently conducted three times.

Cell migration and invasion analysis. To examine the effects of miR-136 on cell migration and invasion, cell assays were performed using a 24 -well transwell chamber ( $8 \mu \mathrm{m}$ pore size). For the transwell migration assays, the cells transfected with mimics, inhibitor or respective miR-negative controls were added to the top chamber at a density of $1 \times 10^{5}$ cells/well. For the invasion assays, $2 \times 10^{5}$ cells were plated in the upper compartment with Matrigel-coated membranes (Corning Life Sciences, Bedford, MA, USA). The cells were subsequently incubated in serum-free RPMI-1640 medium at $37^{\circ} \mathrm{C}$ for $24 \mathrm{~h}$. The lower compartment contained $300 \mu 1$ RPMI-1640 medium supplemented with $20 \%$ FBS, which was used as the chemotactic factor. Following incubation for $24 \mathrm{~h}$, the cells that had migrated into the lower compartment were fixed in $3.7 \%$ formaldehyde for $5 \mathrm{~min}$ and stained with $0.1 \%$ crystal violet for $15 \mathrm{~min}$ at room temperature. The number of cells was counted using a light microscope (magnification, x200). Each experiment was repeated in triplicate.

Dual-luciferase reporter assay. The putative targeting gene, migration and invasion enhancer 1 (MIEN1), of miR-136 was predicted using web-based miRNA databases, Targetscan (http://targetscan.org), miRanda (http://www.microrna.org) and 
Table I. Association between miR-136 expression and clinical characteristics of patients with osteosarcoma.

miR-136 expression

\begin{tabular}{|c|c|c|c|c|}
\hline Clinical characteristics & Cases $(n=116)$ & High $(n=50)$ & Low $(n=66)$ & P-value \\
\hline Sex & & & & 0.283 \\
\hline Male & 56 & 27 & 29 & \\
\hline Female & 60 & 23 & 37 & \\
\hline Age & & & & 0.791 \\
\hline$<18$ & 61 & 27 & 34 & \\
\hline$\geq 18$ & 55 & 23 & 32 & \\
\hline Tumor site & & & & 0.373 \\
\hline Distal femur & 54 & 27 & 27 & \\
\hline Proximal tibia & 41 & 15 & 26 & \\
\hline Others & 21 & 8 & 13 & \\
\hline Enneking staging (19) & & & & 0.030 \\
\hline I-II & 68 & 35 & 33 & \\
\hline III & 48 & 15 & 33 & \\
\hline Distant metastasis & & & & 0.016 \\
\hline Absent & 57 & 31 & 26 & \\
\hline Present & 59 & 19 & 40 & \\
\hline
\end{tabular}

miR-136, microRNA-136.
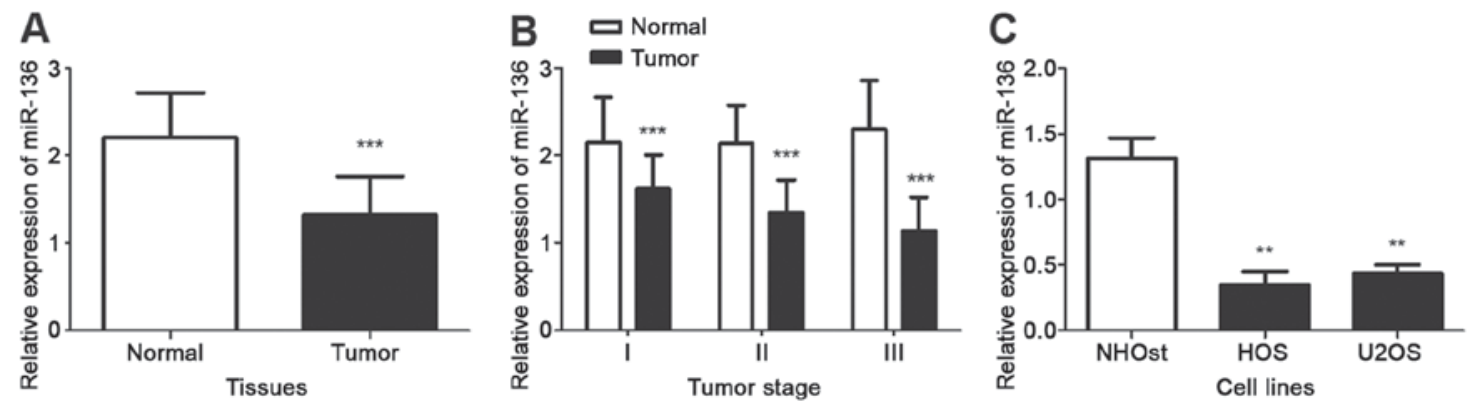

Figure 1. Expression of miR-136 measured by reverse transcription-quantitative polymerase chain reaction. (A) Expression of miR-136 in 116 paired OS tissues and matched adjacent normal tissues. miR-136 expression was decreased in OS tissues. ${ }^{* * *} \mathrm{P}<0.001$ vs. normal. (B) Expression of miR-136 in the tumor tissues at different Enneking stages, compared with matched adjacent normal tissues. ${ }^{* * *} \mathrm{P}<0.001$ vs. respective control. (C) Expression of miR-136 in cells. The expression of miR-136 was decreased in OS cells compared with the normal cells. ${ }^{* *} \mathrm{P}<0.01$ vs. NHOst. miR-136, microRNA-136; OS, osteosarcoma.

miRNA-PicTar (https://dorina.mdc-berlin.de/), all of which used the $3^{\prime}$-UTR as the target region to determine miRNA recognition elements, and subsequently verified by a dual-luciferase reporter assay. The 3'-UTR sequence of MIEN1 was amplified and subcloned into the pGL3 luciferase reporter vector (Promega Corporation). Cells were cotransfected with wild-type (WT) or mutant (MUT) 3'-UTR vectors and miR-136 mimics, inhibitors or controls using Lipofectamine ${ }^{\circledR} 2000$. After 36 h, the luciferase activities of the cells were determined with the Dual-Luciferase Assay System (Promega Corporation) according to the manufacturer's protocol. The firefly luciferase activities were normalized to Renilla luciferase activity. All the experiments were performed in triplicate.

Statistical analysis. Statistical analysis was conducted using SPSS 21.0 (IBM Corp., Armonk, NY, USA) and GraphPad
Prism 5 (GraphPad Software, Inc., La Jolla, CA, USA), and the data are presented as the mean \pm standard deviation. One-way analysis of variance with Tukey's post hoc test was used for multiple comparisons. The association between the clinicopathological characteristics of the patients and miR-136 was analyzed by the $\chi^{2}$ test. The association between overall survival and miR-136 expression was estimated using the Kaplan-Meier method with a log-rank test. The prognostic effects of each clinical characteristic were determined using a Cox regression analysis. $\mathrm{P}<0.05$ was considered to indicate a statistically significant difference.

\section{Results}

Expression of miR-136 in tissue specimens and cells. The expression of miR-136 in 116 paired OS tissue specimens and 


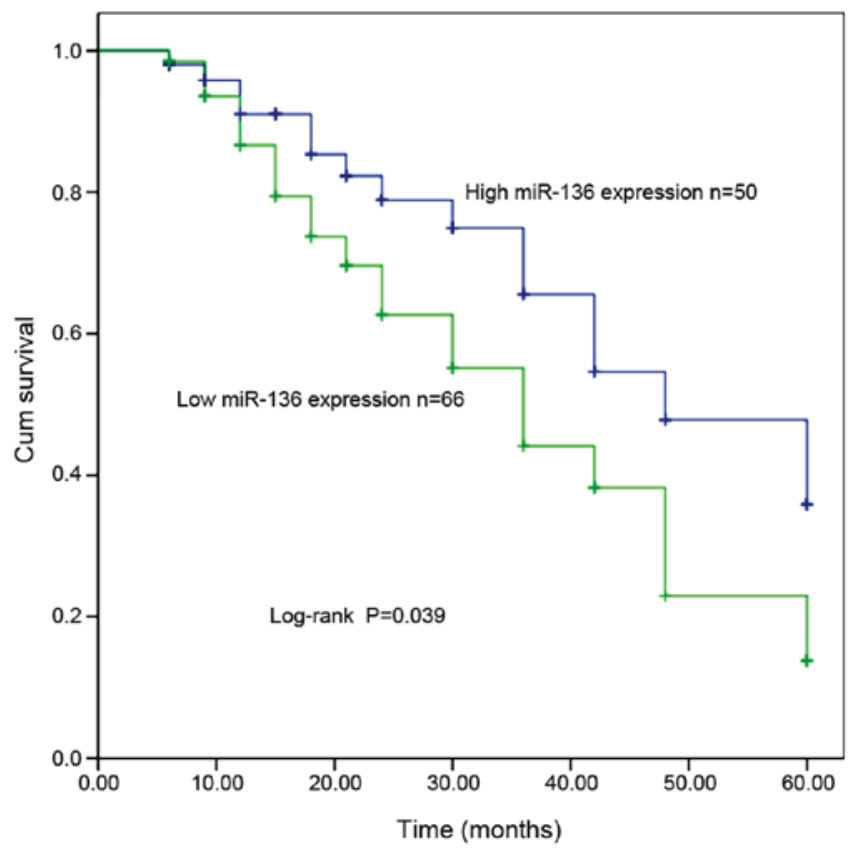

Figure 2. Analysis of survival curves in 116 patients with osteosarcoma by Kaplan-Meier survival analysis. Patients with decreased miR-136 expression demonstrated shorter overall survival compared with patients with increased expression levels. miR-136, microRNA-136; cum, cumulative.

cell lines were detected by RT-qPCR. As presented in Fig. 1A, the expression of miR-136 was significantly decreased in OS tissues compared with matched adjacent non-tumorous tissues $(\mathrm{P}<0.001)$. Furthermore, the expression of miR-136 in tumor tissues at different Enneking stages (19), including stage I ( $n=30)$, stage II $(n=38)$, stage III $(n=48)$, was analyze and compared with the expression in matched normal tissues. The expression of miR-136 in tumor tissues at each stage was significantly decreased compared with matched normal tissues (all $\mathrm{P}<0.05$; Fig. 1B). The expression of miR-136 was consistently decreased in the OS cell lines, HOS and U2OS, compared with the normal human OS cell line NHOst (both $\mathrm{P}<0.05$; Fig. 1C). These results suggested that miR-136 may be a tumor suppressor in OS.

Association of miR-136 expression with clinical characteristics of patients with OS. Relative miR-136 expression in patients with OS was associated with specific clinicopathological characteristics. According to the mean expression level of miR-136 (1.329), the patients were divided into a low miR-136 expression group $(n=66 ; 0.46-1.31)$ and a high expression group $(n=50 ; 1.34-2.48)$. The analysis results are presented in Table I. The expression of miR-136 was associated with Enneking stage $(\mathrm{P}=0.030)$ and distant metastasis $(\mathrm{P}=0.016)$. There was no association between miR-136 expression levels and other clinicopathological characteristics, including sex, age and tumor site $(\mathrm{P}>0.05$; Table I).

Association between miR-136 expression and overall survival time of patients with $O S$. To investigate the prognostic factor of miR-136 expression in OS, Kaplan-Meier and Cox proportional hazard regression model analyses were performed. As presented in Fig. 2, the survival time of patients with low miR-136 expression was shorter compared with patients with high miR-136 expression (log-rank test; $\mathrm{P}=0.039$ ). Univariate and multivariate Cox regression analysis results demonstrated that miR-136 expression (hazard ratio $=0.496 ; 95 \%$ confidence interval $=0.250-0.987$; $\mathrm{P}=0.046$; Table II) may be an important prognostic factor and may thus be an independent biomarker in patients with OS.

Overexpression of miR-136 inhibits proliferation of OS cells. As miR-136 expression was negatively associated with the survival time of the patients, the functional role of miR-136 and its effects on tumor cell proliferation, migration and invasion were investigated. The normal osteoblast cell line NHOst and two OS cell lines HOS and U2OS were transfected with miR-136 mimics, inhibitor or their respective miR-negative controls to regulate the expression of miR-136 in the tumor cells. The RT-qPCR results demonstrated that the expression of miR-136 in OS cells transfected with the miR-136 mimics was significantly increased compared with the cells transfected with the negative control and mock $(\mathrm{P}<0.05$; Fig. $3 \mathrm{~A})$. The results additionally demonstrated that the expression of miR-136 in OS cells transfected with miR-136 inhibitor was decreased compared with miR-136 expression in the cells with the negative control and mock $(\mathrm{P}<0.05$; Fig. $3 \mathrm{~A})$. The expression of miR-136 in the normal osteoblast cell line NHOst was increased in cells transfected with miR-136 mimics and decreased in cells transfected with miR-136 inhibitor, although these differences were not considered statistically significant (P>0.05; Fig. 3A).

An MTT assay was used to measure cell proliferation. The results demonstrated that upregulation of miR-136 inhibited OS cell proliferation $(\mathrm{P}<0.05$; Fig. $3 \mathrm{~B})$. In contrast, an inhibitor of miR-136 had the opposite effect, increasing OS cell proliferation compared with cells transfected with respective negative controls or mock $(\mathrm{P}<0.05$; Fig. 3B). Although cell proliferation was inhibited in NHOst cells transfected with miR-136 mimics and promoted in cells transfected with miR-136 inhibitor, the differences were not statistically significant compared with the controls ( $\mathrm{P}>0.05$; Fig. 3B). Colony formation assays demonstrated that overexpression of miR-136 by miR-136 mimic inhibited colony formation, while inhibition of miR-136 promoted colony formation $(\mathrm{P}<0.001$; Fig. $3 \mathrm{C})$; however, the differences in colony count, relative to NHOst cells, was not considered statistically significant ( $\mathrm{P}>0.05$; Fig. $3 \mathrm{C})$.

Overexpression of miR-136 decreases the migratory and invasive capacities of OS cells. In addition to proliferation, cell migration and invasion were measured using transwell and Matrigel assays, respectively. The assay results demonstrated that OS cells transfected with miR-136 mimics exhibited significantly decreased migratory and invasive capacity compared with the negative control and mock groups $(\mathrm{P}<0.05$; Fig. 4). The OS cells transfected with miR-136 inhibitor promoted the capacity of migration and invasion, compared with cells transfected with negative control and mock $(\mathrm{P}<0.05$, Fig. 4). Similar to cell proliferation, cell migration and invasion in NHOst cells transfected with the miR-136 mimics or inhibitor demonstrated similar trends to the OS cells, although the differences were not considered statistically significant ( $\mathrm{P}>0.05$; Fig. 4).

MIEN1 is a direct target of miR-136 in OS cells. MIEN1 was predicted to be a target of miR-136 (Fig. 5A). A luciferase reporter assay was used to investigate this hypothesis. As 
Table II. Univariate and multivariate Cox analysis of miR-136 expression in patients with osteosarcoma.

\begin{tabular}{|c|c|c|c|c|c|c|}
\hline \multirow[b]{2}{*}{ Characteristics } & \multicolumn{3}{|c|}{ Univariate analysis } & \multicolumn{3}{|c|}{ Multivariate analysis } \\
\hline & HR & $95 \% \mathrm{CI}$ & P-value & HR & $95 \% \mathrm{CI}$ & P-value \\
\hline miR-136 & 0.496 & $0.250-0.987$ & 0.046 & 0.496 & $0.250-0.987$ & 0.046 \\
\hline Sex & 1.230 & $0.670-2.260$ & 0.504 & - & - & - \\
\hline Age & 1.221 & $0.669-2.230$ & 0.516 & - & - & - \\
\hline Tumor site & - & - & 0.390 & - & - & - \\
\hline Tumor site (1) & 1.715 & $0.742-3.964$ & 0.207 & - & - & - \\
\hline Tumor site (2) & 1.702 & $0.738-3.926$ & 0.212 & - & - & - \\
\hline Enneking staging (19) & 1.177 & $0.636-2.179$ & 0.604 & - & - & - \\
\hline Distant metastasis & 0.766 & $0.425-1.380$ & 0.375 & - & - & - \\
\hline
\end{tabular}

-, no associated data; miR-136, microRNA-136; HR, hazard ratio; CI, confidence interval.


Figure 3. Effects of miR-136 expression on proliferation of the OS cells HOS and U2OS compared with the normal osteoblast cell line NHOst. Each treatment group was measured at least three times. (A) Expression of miR-136 in NHOst, HOS and U2OS cells transfected with miR-136 mimics, miR-136 inhibitor or their respective negative controls. (B) Cell viability was measured in OS cells that were transfected with miR-136 mimics, inhibitor or negative controls by an MTT assay. The cell viability in NHOst was not significantly different. (C) Proliferation of OS cells and the normal osteoblast cell line NHOst was detected by a colony formation assay (magnification, $\mathrm{x} 40$ ). Quantification of the colony count. ${ }^{\&} \mathrm{P}<0.05$, ${ }^{\& \& \&} \mathrm{P}<0.001 \mathrm{vs}$. mimic-NC; ${ }^{*} \mathrm{P}<0.05$, ${ }^{\# \# \#} \mathrm{P}<0.001 \mathrm{vs}$. inhibitor-NC; ${ }^{*} \mathrm{P}<0.05,{ }^{* * *} \mathrm{P}<0.001$ vs. mock. miR-136, microRNA-136; NC, negative control; OD, optical density; ns, not significant.

presented in Fig. 5B, the luciferase activity assay results demonstrated that cotransfection of the miR-136 mimics inhibited the luciferase activity of the reporter containing the WT MIEN1 3'-UTR sequence; however, failed to suppress that containing the MUT MIEN1 3'UTR. In contrast, the luciferase activity of the reporter with the WT 3'-UTR of MIEN1 was increased in the cells transfected with the miR-136 inhibitor; however, the luciferase activity did not alter with the MUT 3'-UTR (Fig. 5B). These results suggested that MIEN1 may be a direct functional target of miR-136 in OS. 

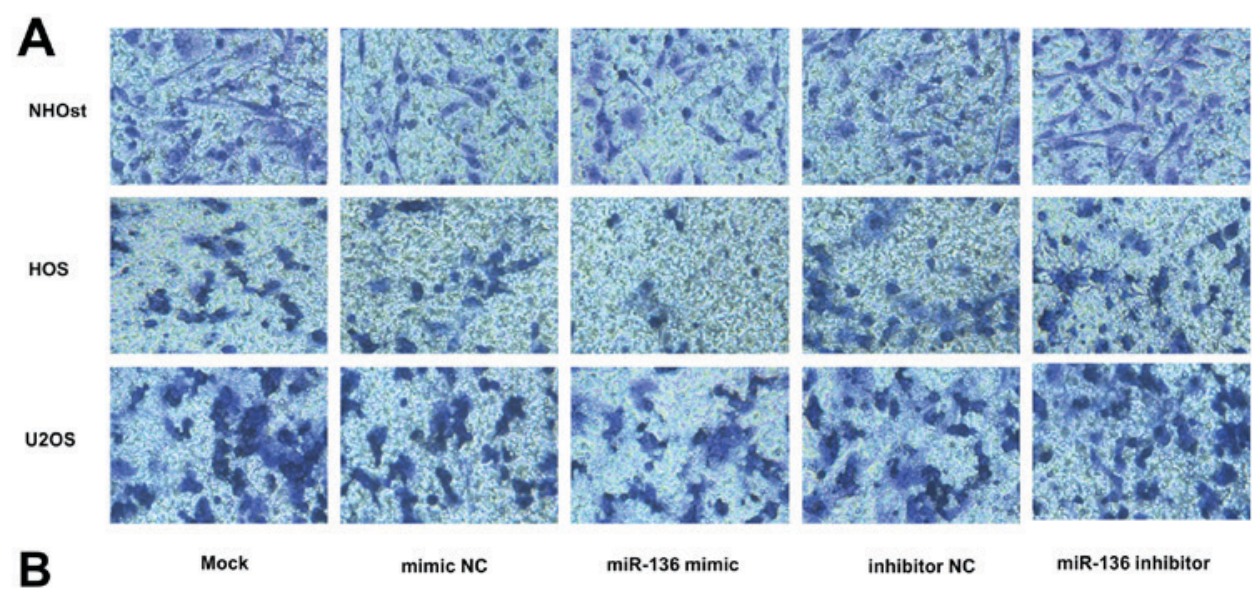

B


mimic NC

miR-136 mimic

inhibitor NC
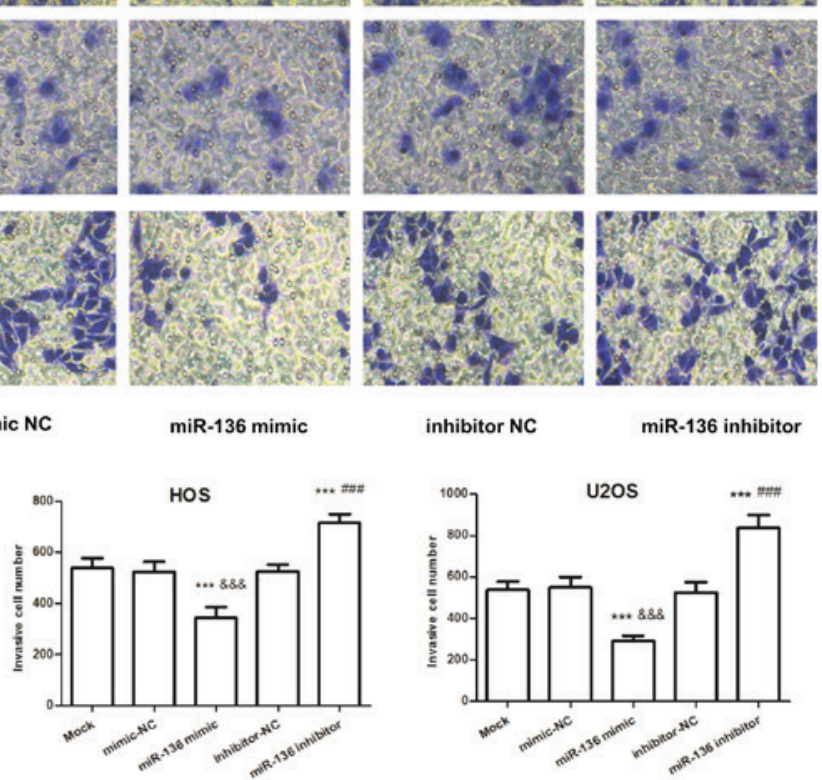

Figure 4. Effects of miR-136 expression on the migration and invasion of the OS cell lines, HOS and U2OS, and normal osteoblast cell line NHOst. (A) Migration analysis of NHOst, HOS and U2OS cells by transwell assays (magnification, x200). (B) Migration of OS cell lines, HOS and U2OS, is suppressed by increasing miR-136 expression and increased by the downregulation of miR-136 expression. (C) Invasion analysis of NHOst, HOS and U2OS cells by Matrigel-precoated transwell assays (magnification, $\mathrm{x} 200$ ). (D) Overexpression of miR-136 by miR-136 mimics decreased cell invasion and downregulation of miR-136 expression increased cell invasion. ${ }^{\& \&} \mathrm{P}<0.01,{ }^{\text {\&\&\& }} \mathrm{P}<0.001$ vs. mimic-NC; ${ }^{\# \# *} \mathrm{P}<0.001$ vs. inhibitor-NC; ${ }^{* *} \mathrm{P}<0.01,{ }^{* * *} \mathrm{P}<0.001$ vs. mock. miR-136, microRNA-136; NC, negative control; ns, not significant.

\section{Discussion}

The low prevalence and large heterogeneity of OS make it difficult to improve patient survival (23). The specific tumor markers and prognostic factors of OS have important clinical significance. A number of previous studies demonstrated a critical role for molecular biomarkers in tumor pathogenesis (24-26). In OS, specific prognostic biomarkers have additionally been identified. Hou et al (27) demonstrated that cyclin-dependent kinase-1 gene expression was increased in patients with OS and may thus serve as a biomarker to predict the occurrence, development and prognosis of OS. Fernanda Amary et al (28) demonstrated that 

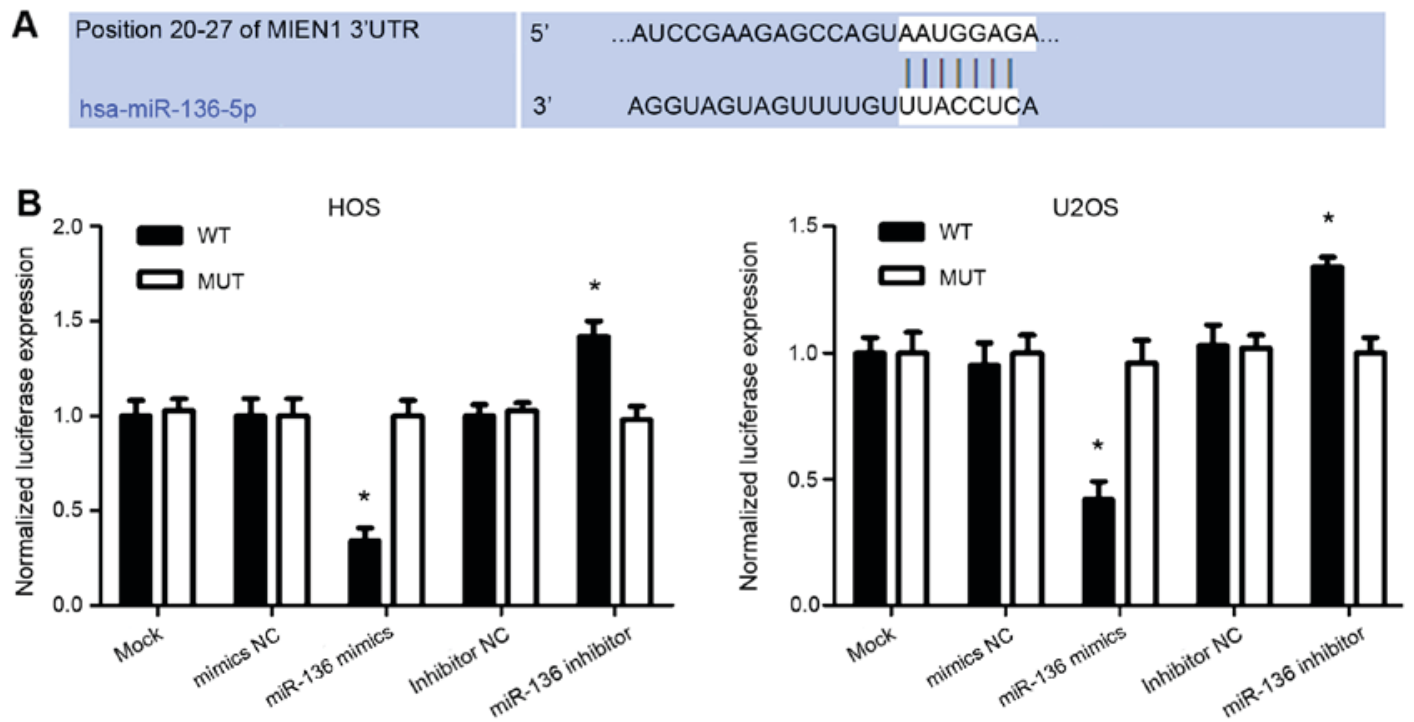

Figure 5. MIEN1 is a target of miR-136 in osteosarcoma cells. (A) Bioinformatics prediction of miR-136 binding sites in the 3'-UTR of the human MIEN1 gene (B) Luciferase reporter plasmid containing the WT or MUT MIEN1 3'-UTR was cotransfected into HOS and U2OS cells with miR-136 mimics or inhibitors. Luciferase activity of the cells was assayed at $36 \mathrm{~h}$ after transfection and the values were normalized to the controls. " $\mathrm{P}<0.05$ vs. respective MUT. miR-136, microRNA-136; NC, negative control; WT, wild-type; MUT, mutant; MIEN1, migration and invasion enhancer 1; 3'-UTR, 3' untranslated region.

fibroblastic growth factor receptor 1 gene amplification in OS was associated with a poor response to neoadjuvant chemotherapy. Liang et al (29) demonstrated that Phospholipase A2 Group XVI expression was increased in OS and may thus serve as a prognostic factor in patients with primary OS for predicting the development of metastases and poor survival. Together, these previous studies suggested that identification of cancer-associated biomarkers for tumor progression and outcome may help to predict patient prognosis and treatment strategies.

A number of miRNAs have been demonstrated to contribute to the development of cancer and to serve as biomarkers for the diagnosis, prognosis or treatment of different types of cancer (30-32). Taheriazam et al (33) demonstrated that miRNA-130b expression was increased in OS tissues, whereas, the level of miRNA-218 expression was downregulated; these miRNAs may serve as potential biomarkers in the early detection of OS. In this study, it was indicated that the expression of miR-136 was downregulated in the patients with OS, which is consistent with the results in previous studies $(34,35)$. For instance, miR-136 was downregulated and acted as a tumor suppressor in colon cancer (34). In renal cell carcinoma, miR-136 was reported to be downregulated and associated with renal cell carcinoma cellular functions (35). To improve the understanding of the role of miR-136 in OS, its expression patterns and association with the clinicopathological features of the patients with OS were investigated. In the present study, the expression of miR-136 was decreased in OS tissues and cells compared with the corresponding normal controls. Furthermore, the expression level of miR-136 was associated with Enneking staging and distant metastasis in patients with OS. These results indicated that miR-136 expression is negatively associated with tumorigenesis and progression of OS, which suggested that miR-136 may serve a tumor suppressor role in OS tumorigenesis.

To evaluate the association of miR-136 with the overall survival of patients with OS, Kaplan-Meier and Cox regression analyses were used. Kaplan-Meier analysis demonstrated that patients in the low miR-136 expression group had shorter survival times compared with patients with high miR-136 expression. According to Cox regression analysis, miR-136 expression was associated with the prognosis of OS. Additionally, it may be an independent prognostic marker in OS.

Previous studies demonstrated the effects of miR-136 on biological behaviors during cancer progression $(15,21)$. miR-136 inhibited colon cancer cell proliferation and invasion, which may serve as a potential therapeutic target for colon cancer (15). However, the functions of miR-136 in OS cells have not yet been studied, to the best of the authors' knowledge. In the present study, the effects of miR-136 on the biological behavior of OS cells were assessed to demonstrate a functional involvement of miR-136 during OS progression. The results demonstrated that overexpression of miR-136 may inhibit tumor cell proliferation, migration and invasion, which suggested a potential tumor suppressor role for miR-136.

MIEN1 is located in the $17 \mathrm{q} 12$ region of the human chromosome and has been demonstrated to be dysregulated in various cancer tissues $(36,37)$. A number of miRNAs were demonstrated to perform biological functions by targeting MIEN1, including miRNA-26b (38), miRNA-940 (39) and miRNA-136 (34). Ren et al (34) demonstrated that miR-136 directly targeted the 3'-UTR of MIEN1 in colon cancer. In the present study, a luciferase reporter assay demonstrated that MIEN1 is a direct functional target of miR-136 in OS. In a recent study, miR-136 expression was decreased in triple-negative breast cancer, and suppressed mesenchymal invasion and metastasis by targeting RAS protein activator-like 2 (40). A previous study by Yang et al (41) demonstrated that miR-136 directly targeted mothers against decapentaplegic homolog (Smad)2 and Smad3 in transforming growth factor- $\beta /$ Smad signaling, leading to decreased migration and invasiveness of lung adenocarcinoma cell lines. However, the detailed molecular mechanisms of miR-136 downregulation and the effects of targeting MIEN1 in OS require further investigation. Additionally, due to the limitation of sample size, further studies with larger research cohorts are necessary. 
In conclusion, the present findings demonstrated that miR-136 was downregulated in OS cells and tissues of patients with OS. Furthermore, overexpression of miR-136 resulted in the inhibition of cell proliferation, migration and invasion in OS cells. Further investigation of miR-136 identified that MIEN1 was a potential target of miR-136. Together, these data suggested that miR-136 may be a prognostic biomarker and potential therapeutic target for patients with OS.

\section{Acknowledgements}

Not applicable.

\section{Funding}

The present study was funded by The Science and Technology Development Plan Project of Qingdao Economic and Technological Development Zone (grant no. 2014-1-78; China).

\section{Availability of data and materials}

The analyzed datasets generated during the present study are available from the corresponding author on reasonable request.

\section{Authors' contributions}

YC and YW initiated and designed the work, analyzed the data, and wrote the manuscript. XH and GW collected clinical tissues, performed RNA extraction and RT-qPCR assays, and corresponding data analysis. ZW performed cell experiments. All authors have read and approved the final version of this manuscript.

\section{Ethics approval and consent to participate}

All patients agreed to participate in the present study and provided written informed consent prior to surgery, and the Ethics Committee of The Affiliated Hospital of Qingdao University (Qingdao, China) approved the protocol.

\section{Patient consent for publication}

Not applicable.

\section{Competing interests}

The authors declare that they have no competing interests.

\section{References}

1. Ottaviani G and Jaffe N: The epidemiology of osteosarcoma. Cancer Treat Res 152: 3-13, 2009.

2. Ritter J and Bielack SS: Osteosarcoma. Ann Oncol 21 (Suppl): vii320-325, 2010.

3. Jones KB, Ferguson PC, Lam B, Biau DJ, Hopyan S, Deheshi B, Griffin AM, White LM and Wunder JS: Effects of neoadjuvant chemotherapy on image-directed planning of surgical resection for distal femoral osteosarcoma. J Bone Joint Surg Am 94: 1399-1405, 2012.

4. Wong KC, Lee V, Shing MM and Kumta S: Surgical resection of relapse may improve postrelapse survival of patients with localized osteosarcoma. Clin Orthop Relat Res 471: 814-819, 2013.

5. Gill J, Ahluwalia MK, Geller D and Gorlick R: New targets and approaches in osteosarcoma. Pharmacol Ther 137: 89-99, 2013.
6. Meazza C and Scanagatta P: Metastatic osteosarcoma: A challenging multidisciplinary treatment. Exp Rev Anticancer Ther 16: 543-556, 2016.

7. Farazi TA, Hoell JI, Morozov P and Tuschl T: MicroRNAs in human cancer. Adv Exp Med Biol 774: 1-20, 2013.

8. Wang G, Zhu S, Gu Y, Chen Q, Liu X and Fu H: MicroRNA-145 and microRNA-133a inhibited proliferation, migration, and invasion, while promoted apoptosis in hepatocellular carcinoma cells via targeting FSCN1. Dig Dis Sci 60: 3044-3052, 2015.

9. Li C, Zhao L, Chen Y, He T, Chen X, Mao J, Li C, Lyu J and Meng QH: MicroRNA-21 promotes proliferation, migration, and invasion of colorectal cancer, and tumor growth associated with down-regulation of sec23a expression. BMC Cancer 16: 605, 2016.

10. Nishikawa R, Goto Y, Kurozumi A, Matsushita R, Enokida H, Kojima S, Naya Y, Nakagawa M, Ichikawa T and Seki N: MicroRNA-205 inhibits cancer cell migration and invasion via modulation of centromere protein $\mathrm{F}$ regulating pathways in prostate cancer. Int J Urol 22: 867-877, 2015.

11. Zhu J, Liu F, Wu Q and Liu X: MiR-221 increases osteosarcoma cell proliferation, invasion and migration partly through the downregulation of PTEN. Int J Mol Med 36: 1377-1383, 2015.

12. $\mathrm{Xu} \mathrm{M}$, Jin $\mathrm{H}, \mathrm{Xu} \mathrm{CX}, \mathrm{Bi} \mathrm{WZ}$ and Wang Y: MiR-34c inhibits osteosarcoma metastasis and chemoresistance. Med Oncol 31: 972, 2014.

13. Zhao H, Ma B, Wang Y, Han T, Zheng L, Sun C, Liu T, Zhang Y, Qiu X and Fan Q: miR-34a inhibits the metastasis of osteosarcoma cells by repressing the expression of CD44. Oncol Rep 29: 1027-1036, 2013.

14. Mosakhani N, Pazzaglia L, Benassi MS, Borze I, Quattrini I, Picci $\mathrm{P}$ and Knuutila S: MicroRNA expression profiles in metastatic and non-metastatic giant cell tumor of bone. Histol Histopathol 28: 671-678, 2013.

15. Yuan Q, Cao G, Li J, Zhang Y and Yang W: MicroRNA-136 inhibits colon cancer cell proliferation and invasion through targeting liver receptor homolog-1/Wnt signaling. Gene 628: 48-55, 2017.

16. Lu HJ, Jin PY, Tang Y, Fan SH, Zhang ZF, Wang F, Wu DM, $\mathrm{Lu} \mathrm{J}$ and Zheng YL: microRNA-136 inhibits proliferation and promotes apoptosis and radiosensitivity of cervical carcinoma through the NF-kappaB pathway by targeting E2F1. Life Sci 199: 167-178, 2018.

17. Jia H, Wang H, Yao Y, Wang C and Li P: miR-136 inhibits malignant progression of hepatocellular carcinoma cells by targeting cyclooxygenase 2. Oncol Res 26: 967-976, 2018.

18. Biermann JS, Chow W, Reed DR, Lucas D, Adkins DR Agulnik M, Benjamin RS, Brigman B, Budd GT, Curry WT, et al: NCCN guidelines insights: Bone cancer, version 2.2017. J Natl Compr Canc Netw 15: 155-167, 2017.

19. Cates JM: Comparison of the AJCC, MSTS, and modified spanier systems for clinical and pathologic staging of osteosarcoma. Am J Surg Pathol 41: 405-413, 2017.

20. Livak KJ and Schmittgen TD: Analysis of relative gene expression data using real-time quantitative PCR and the 2(-Delta Delta C(T)) method. Methods 25: 402-408, 2001.

21. Shen S, Yue H, Li Y, Qin J, Li K, Liu Y and Wang J: Upregulation of miR-136 in human non-small cell lung cancer cells promotes Erk1/2 activation by targeting PPP2R2A. Tumour Biol 35: 631-640, 2014.

22. Zhang H, Cai X, Wang Y, Tang H, Tong D and Ji F: microRNA-143, down-regulated in osteosarcoma, promotes apoptosis and suppresses tumorigenicity by targeting Bcl-2. Oncol Rep 24: 1363-1369, 2010.

23. Poos K, Smida J, Maugg D, Eckstein G, Baumhoer D, Nathrath M and Korsching E: Genomic heterogeneity of osteosarcoma-shift from single candidates to functional modules. PLoS One 10: e0123082, 2015.

24. Hass HG, Jobst J, Vogel U, Scheurlen M and Nehls O: Overexpression of tumor-associated trypsin inhibitor (SPINK1/TATI) in hepatitis C-associated hepatocellular carcinoma: Potential implications for viral hepatocarcinogenesis. Oncol Res Treat 37: 732-738, 2014.

25. Karakus N, Kara N, Ulusoy AN, Ozaslan C, Tural S and Okan I: Evaluation of CYP17A1 and LEP gene polymorphisms in breast cancer. Oncol Res Treat 38: 418-422, 2015.

26. Dimberg J, Olsen RS, Skarstedt M, Lofgren S, Zar N and Matussek A: Polymorphism of the p38 $\beta$ gene in patients with colorectal cancer. Oncol Lett 8: 1093-1095, 2014.

27. Hou G, Chen B, Xu W, Zhao H, Liu K and Yao H: Expression level of CDC2 gene in osteosarcoma and its clinical significance. Oncol Lett 15: 7884-7888, 2018. 
28. Fernanda Amary M, Ye H, Berisha F, Khatri B, Forbes G Lehovsky K, Frezza AM, Behjati S, Tarpey P, Pillay N, et al: Fibroblastic growth factor receptor 1 amplification in osteosarcoma is associated with poor response to neo-adjuvant chemotherapy. Cancer Med 3: 980-987, 2014.

29. Liang S, Ren Z, Han X, Yang J, Shan L, Li L, Wang B, Zhang Q, $\mathrm{Mu} \mathrm{T}$, Chen K, et al: PLA2G16 expression in human osteosarcoma is associated with pulmonary metastasis and poor prognosis. PLoS One 10: e0127236, 2015.

30. Fesler A, Zhai H and Ju J: miR-129 as a novel therapeutic target and biomarker in gastrointestinal cancer. Onco Targets Ther 7: 1481-1485, 2014.

31. Zavala V, Perez-Moreno E, Tapia T, Camus $\mathrm{M}$ and Carvallo $\mathrm{P}$ : miR-146a and miR-638 in BRCA1-deficient triple negative breas cancer tumors, as potential biomarkers for improved overall survival. Cancer Biomark 16: 99-107, 2016.

32. Jiang Y, Luan Y, Chang H and Chen G: The diagnostic and prognostic value of plasma microRNA-125b-5p in patients with multiple myeloma. Oncol Lett 16: 4001-4007, 2018.

33. Taheriazam A, Talaei AJ, Jamshidi M, Shakeri M, Khoshbakht S, Yahaghi E and Shokrani M: Up-regulation of miR-130b expression level and down-regulation of miR-218 serve as potential biomarker in the early detection of human osteosarcoma. Diagn Pathol 10: 184, 2015.

34. Ren H, Qi Y, Yin X and Gao J: miR-136 targets MIEN1 and involves the metastasis of colon cancer by suppressing epithelial-to-mesenchymal transition. Onco Targets Ther 11: 67-74, 2018.
35. Chen P, Zhao L, Pan X, Jin L, Lin C, Xu W, Xu J, Guan X, Wu X, Wang Y, et al: Tumor suppressor microRNA-136-5p regulates the cellular function of renal cell carcinoma. Oncol Lett 15: 5995-6002, 2018.

36. Rajendiran S, Kpetemey M, Maji S, Gibbs LD, Dasgupta S, Mantsch R, Hare RJ and Vishwanatha JK: MIEN1 promotes oral cancer progression and implicates poor overall survival. Cancer Biol Ther 16: 876-885, 2015.

37. Kpetemey M, Dasgupta S, Rajendiran S, Das S, Gibbs LD, Shetty P, Gryczynski Z and Vishwanatha JK: MIEN1, a novel interactor of Annexin A2, promotes tumor cell migration by enhancing AnxA2 cell surface expression. Mol Cancer 14: 156, 2015.

38. Li D, Wei Y, Wang D, Gao H and Liu K: MicroRNA-26b suppresses the metastasis of non-small cell lung cancer by targeting MIEN1 via NF-kappaB/MMP-9/VEGF pathways. Biochem Biophys Res Commun 472: 465-470, 2016.

39. Rajendiran S, Parwani AV, Hare RJ, Dasgupta S, Roby RK and Vishwanatha JK: MicroRNA-940 suppresses prostate cancer migration and invasion by regulating MIEN1. Mol Cancer 13: 250, 2014.

40. Yan M, Li X, Tong D, Han C, Zhao R, He Y and Jin X: miR-136 suppresses tumor invasion and metastasis by targeting RASAL2 in triple-negative breast cancer. Oncol Rep 36: 65-71, 2016

41. Yang Y, Liu L, Cai J, Wu J, Guan H, Zhu X, Yuan J, Chen S and Li M: Targeting Smad2 and Smad3 by miR-136 suppresses metastasis-associated traits of lung adenocarcinoma cells. Oncol Res 21: 345-352, 2013. 